\begin{tabular}{|c|l|}
\hline Title & Fast migration of fluoride ions in growing anodic titanium oxide \\
\hline Author(s) & Habazaki, H.; Fushimi, K.; Shimizu, K.; Skeldon, P.; Thompson, G.E. \\
\hline Citation & $\begin{array}{l}\text { Electrochemistry Communications, 9(5), 1222-1227 } \\
\text { https://doi.org/10.1016/.elecom.2006.12.023 }\end{array}$ \\
\hline Issue Date & $2007-05$ \\
\hline Doc URL & http://hdl.handle.net/2115/27963 \\
\hline Type & article (author version) \\
\hline File Information & EC9-5.pdf \\
\hline
\end{tabular}

Instructions for use 


\section{Fast Migration of Fluoride Ions in Growing Anodic Titanium Oxide}

H. Habazaki ${ }^{\text {a, }}$, K. Fushimi ${ }^{\text {a }}$, K. Shimizu ${ }^{\text {b }}$, P. Skeldon ${ }^{\mathrm{c}}$ and G.E. Thompson ${ }^{\mathrm{c}}$

${ }^{a}$ Graduate School of Engineering, Hokkaido University, Sapporo 060-8628, Japan

${ }^{\mathrm{b}}$ University Chemical Laboratory, Keio University, 4-1-1, Hiyoshi, Yokohama 223-8577, Japan

${ }^{\mathrm{c} C}$ Corrosion and Protection Centre, School of Materials, The University of Manchester, P.O. Box 88, Manchester M60 1QD, UK

*Corresponding author: tel; +81-11-706-6575, fax; +81-11-706-6575, e-mail address; habazaki@eng.hokudai.ac.jp (H. Habazaki) 
Abstract

The rapid inward migration of fluoride ions in growing anodic titanium oxide under a high electric field has been elucidated by anodizing a Ti-12 at\% silicon alloy, where film growth proceeds at nearly $100 \%$ efficiency in selected electrolytes. Further, incorporated silicon species in the anodic film are immobile, acting as marker species. The migration rate of fluoride ions is determined precisely by three-stage anodizing, consisting of initial anodic film formation at a constant current density to $50 \mathrm{~V}$ in ammonium pentaborate electrolyte, subsequent incorporation of fluoride ions by reanodizing to $55 \mathrm{~V}$ in ammonium fluoride electrolyte and, finally, anodizing again in ammonium pentaborate electrolyte at high current efficiency. The resultant films were analyzed by glow discharge optical emission spectroscopy to reveal the depth distribution of fluoride ions and the location of the silicon marker species. The fluoride ions migrate inward at twice the rate of $\mathrm{O}^{2-}$ ions. Consequently, anodizing of titanium in fluoride-containing electrolytes develops a fluoride-rich layer that separates the alloy substrate from the anodic oxide, with eventual detachment of the film from the substrate.

Keywords; anodic film, titanium, ionic transport, fluoride ions, GDOES 


\section{Introduction}

Titanium oxide nanotube arrays, formed by anodic oxidation of titanium in fluoride-containing electrolytes, are the subject of current attention due to fundamental interest in the generation self-organized porous layers and their potential applications in photocatalysis, photoelectrolysis, photovoltanics and as sensors [1].

Formation of porous anodic oxides on titanium in hydrofluoric acid electrolyte was first reported in 1999 [2], with its nanotubular structure demonstrated by Grimes and co-workers in 2001 [3]. Further studies have focused on precise control of nanotube morphology, with the composition of the electrolyte playing a key role in controlling the morphology [4-10]. The superior properties of anodic titanium oxide nanotube layers, such as photocatalytic and hydrogen sensing properties, as well as control of surface wettability, have also been demonstrated [1, 11-16]. However, during formation of the porous anodic titanium oxide film, detachment of the film is often encountered, generating a layered anodic film [17].

The detachment of the anodic film may be associated with fluoride ions incorporated into the anodic film. Although the behaviour of fluoride ions during formation of anodic films on titanium in fluoride-containing electrolyte is not well understood, it is known that during anodizing of tantalum, the inward mobility of fluoride ions is twice that of $\mathrm{O}^{2-}$ ions, leading to the development of a thin layer of $\mathrm{TaF}_{5}$ that separates the substrate from the anodic oxide film $[18,19]$. Poor adhesion of the resultant anodic film, associated with the fluoride layer, has also been demonstrated [18]. Thus, it is possible that film detachment on titanium is associated with the formation of a titanium fluoride layer between the oxide film and metal substrate that results from the fast inward migration of fluoride ions during anodic film growth under the high electric field.

In the present study, the migration rate of fluoride ions during growth of anodic titanium oxide has been determined for the first time. In order to elucidate precisely the 
migration rate of fluoride ions, anodizing conditions have been selected that allow barrier type anodic film formation at high current efficiency. Normally growth of barrier type anodic films on high purity titanium at high current efficiency is limited to low voltages ( $10 \mathrm{~V})$, because of an amorphous-to-crystalline transition, with subsequent oxygen generation on further film growth $[20,21]$. The authors have revealed that the amorphous-to-crystalline transition is effectively suppressed to increased voltages by incorporation of foreign species from the substrate into the anodic oxide [22-27]. In particular, silicon species, incorporated from a Ti-Si alloy delay the transition to increased voltages; further, silicon species are immobile during film growth, thereby acting as marker species. From the depth distribution of the marker species, it is evident that the amorphous anodic titanium oxide grows at the metal/film and film/electrolyte interfaces by simultaneous migration of anions inward and cations outward respectively, with a transport number of cations of $0.39 \pm 0.03$ [24]. Further, from anodizing of a Ti-6 at\% Si alloy in various electrolytes, the mobilities of a range of foreign species, derived from the associated electrolyte anions, have also been determined precisely $[23,24]$. Good correlation has been found between the migration rates of outwardly migrating species and their single metal-oxygen bond energies, such that species with strong metal-oxygen bonds migrate more slowly than titanium cations during film growth [24].

In the present work, silicon-stabilized amorphous anodic titanium oxide has been grown to $50 \mathrm{~V}$ at high current efficiency in fluoride-free electrolyte (Fig. 1(a)). Subsequently, fluoride ions are incorporated into the anodic film by anodizing in ammonium fluoride electrolyte to $55 \mathrm{~V}$ (Fig. 1(b)). The depth distribution of fluoride ions after further anodizing in the fluoride-free electrolyte (Fig. 1(c)) has been determined by glow discharge optical emission spectroscopy (GDOES). The depth of fluoride ions with respect to the thickness of the anodic film, $\left(d / d_{0}\right)$, at a formation voltage $E$ is determined by the migration rate of fluoride ions relative to that of $\mathrm{O}^{2-}$ ions, $u_{\mathrm{F}}-u_{\mathrm{O}} 2-$ and the transport numbers of cations, $t_{+}$, and anions, $t_{\text {-, }}$ 
using the following equation.

$$
\frac{d}{d_{0}}=\left(t_{+}+\frac{u_{F^{-}}}{u_{O^{2-}}} t_{-}\right)\left(1-\frac{55}{E}\right)
$$

\section{Experimental}

Ti-12 at\% Si alloy films, approximately 200 nm thick, were prepared by dc magnetron sputtering on a silicon wafer. The target consisted of a 99.9\% pure titanium disk of $100 \mathrm{~mm}$ diameter and $6 \mathrm{~mm}$ thickness; two square silicon plates, with $15 \mathrm{~mm}$ sides, were placed symmetrically on the region of the target that is sputtered. In order to generate deposited films of uniform composition and thickness, the substrate holders were rotated around the central axis of the chamber as well as their own axis.

The deposited films were anodized to $50 \mathrm{~V}$ at a constant current density of $50 \mathrm{~A} \mathrm{~m}^{-2}$ in stirred $0.1 \mathrm{~mol} \mathrm{dm}^{-3}$ ammonium pentaborate electrolyte at $293 \mathrm{~K}$. Fluoride ions were then incorporated into the initial anodic oxide by reanodizing to $55 \mathrm{~V}$ at $10 \mathrm{~A} \mathrm{~m}^{-2}$ in $0.1 \mathrm{~mol} \mathrm{dm}^{-3}$ ammonium fluoride electrolyte. Finally, the specimens were anodized further to 80 or $100 \mathrm{~V}$ at $50 \mathrm{~A} \mathrm{~m}^{-2}$ in $0.1 \mathrm{~mol} \mathrm{dm}^{-3}$ ammonium pentaborate electrolyte. The growth of the anodic film in the ammonium pentaborate electrolyte proceeded at nearly $100 \%$ efficiency [24]. For comparison, the deposited films were also anodized to $50 \mathrm{~V}$ in $0.1 \mathrm{~mol} \mathrm{dm}^{-3}$ ammonium fluoride electrolyte at $293 \mathrm{~K}$.

Depth profiles of the anodized specimens were generated using a Jobin-Yvon 5000 RF instrument in a neon atmosphere of 900 Pa by applying RF of $13.56 \mathrm{MHz}$ and power of 50 W. A neon plasma, rather than the generally used argon plasma, was necessary to excite the most intense fluorine line of $685.60 \mathrm{~nm}$ [28]. Light emissions of characteristic wavelengths were monitored throughout the analysis with a sampling time of $0.01 \mathrm{~s}$ to obtain the depth profiles. The wavelengths of the spectral lines used were 365.350, 288.158, 685.602, 130.217 
and $249.678 \mathrm{~nm}$ for titanium, silicon, fluorine, oxygen and boron respectively. The signals were detected from a circular area of approximately $4 \mathrm{~mm}$ diameter.

\section{Results}

The voltage-time curves during anodizing of the sputter-deposited Ti-12 at\% Si alloy

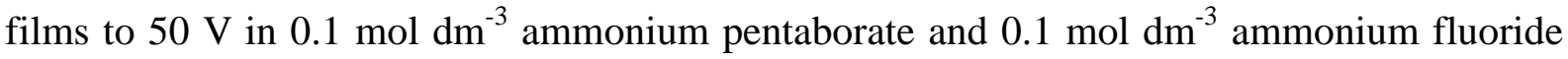
electrolytes (Fig. 2) disclose an initial voltage surge of $\sim 2 \mathrm{~V}$, that is followed by a linear voltage increase with time of slope 1.5 and $0.77 \mathrm{~V} \mathrm{~s}^{-1}$ in ammonium pentaborate and ammonium fluoride electrolytes respectively. The voltage surge at the commencement of anodizing is associated with the presence of an air-formed film on the sputter deposited alloy of approximately $3 \mathrm{~nm}$ thickness. The reduced rate of voltage rise in the ammonium fluoride electrolyte compared with that in the ammonium pentaborate electrolyte, where film growth proceeds at $\sim 100 \%$ efficiency [24], suggests a relatively low current efficiency of film formation in the former electrolyte.

GDOES depth profiles of the anodic film formed to $50 \mathrm{~V}$ in the ammonium fluoride electrolyte (Fig. 3) demonstrate clearly the distributions of the incorporated fluoride ions and the silicon marker species. Fluoride ions are distributed relatively uniformly throughout the outer regions of the anodic film, with an accumulation of fluoride ions evident as the alloy/film interface is approached. The faster inward migration of fluoride ions relative to that of $\mathrm{O}^{2-}$ ions is clearly confirmed. The presence of a relatively broad alloy/film interface region resulted largely from non-uniform sputtering by neon ions within the eroded region of 4 mm diameter.

A further characteristic feature of the present anodic film formed in the fluoride electrolyte is the absence of a silicon-free outer oxide layer; such layers developed after anodizing in the ammonium pentaborate electrolyte (Fig. 4). Thus, for anodizing in the 
ammonium fluoride electrolyte, the outward migrating titanium ions, which reach the film/electrolyte interface, are ejected directly into the electrolyte. Thus, the anodic film material is developed only at the alloy/film interface by inward migration of $\mathrm{O}^{2-}$ ions as well as fluoride ions.

For precise determination of the migration rate of fluoride ions relative to $\mathrm{O}^{2-}$ ions in growing anodic titanium oxide under the high electric field, fluoride ions have been incorporated into an anodic film formed to $50 \mathrm{~V}$ in ammonium pentaborate electrolyte. After reanodizing to $55 \mathrm{~V}$ in ammonium fluoride electrolyte, associated with incorporation of fluoride ions, further film growth was continued to 80 and $100 \mathrm{~V}$ in ammonium pentaborate electrolyte at nearly $100 \%$ efficiency. The depth profiles of the resultant anodic films are revealed in Fig. 4 with the incorporated fluoride ions present as a relatively narrow band within the anodic film. The fluoride band is wider at increased formation voltage, due mainly to the decreased depth resolution of GDOES analysis. The hatched region in Figure (4) of width equivalent to the thickness of the anodic film formed between 50 and $55 \mathrm{~V}$ show schematically the locations of the fluoride containing film region after final anodizing. The depths of the fluoride bands with respect to the thickness of the anodic films formed 80 and $100 \mathrm{~V}$ are 0.46 and 0.73 respectively. The increased relative depth of the fluoride ions with formation voltage again indicates the faster inward migration of fluoride ions relative to $\mathrm{O}^{2-}$ ions. Boron species, incorporated from the borate electrolyte, are present in the outer $~ 20 \%$ of the film thickness, consistent with previous investigations [24]. In contrast to the anodic film formed in the ammonium fluoride electrolyte (Fig. 3), a silicon-free outer layer, of about $42 \%$ of the film thickness, is present in the anodic films formed mostly in the ammonium pentaborate electrolyte. A linear correlation is evident between the depth of the fluoride band relative to the thickness of the anodic film, $d / d_{0}$, and the reciprocal of the formation voltage, $E^{-1}$, (Fig. 5). The linear correlation also suggests that the silicon species, present in the inner 
region of the film, do not influence significantly the inward mobility of fluoride ions.

\section{Discussion}

4.1 Growth of the anodic film on the Ti-12 at\% Si alloy

The linear voltage increase during galvanostatic anodizing of the Ti-12 at\% Si alloy in ammonium pentaborate electrolyte (Fig. 1) indicates growth of an anodic film without oxygen generation, which appears after development of crystalline oxide on high purity titanium. The growth at nearly 100\% efficiency has been confirmed from the charge passed during anodizing and the number of cations in the resultant anodic film, determined by Rutherford backscattering spectroscopy (RBS) [29]. The composition, density and thickness of the anodic film, formed to $100 \mathrm{~V}$ in $0.1 \mathrm{~mol} \mathrm{dm}^{-3}$ ammonium pentaborate electrolyte, determined by RBS and TEM, are summarized in Table 1 [29]. The thickness of the outer silicon-free $\mathrm{TiO}_{2}$ layer, relative to the total film thickness, is 0.42 , which is in agreement with the ratio of the corresponding sputtering times in Fig. 4. Since silicon species are immobile during growth of various anodic oxides, including anodic aluminium oxide [30], niobium oxide [31], tantalum oxide [18, 19]and titanium oxide [23, 24], the transport number of cations, $t_{+}$, can be determined from the ratio of the number of cations in the outer silicon-free layer to the total number of cations in the anodic film, giving 0.42 . The value is consistent with the previously determined values [23, 32].

\subsection{Migration rate of fluoride ions}

Since the transport numbers of cations and anions in the anodic oxide have been determined from the distribution of silicon marker species, the mobility of fluoride ions can be calculated from the depth of fluoride ions in the anodic films and the formation voltage using equation (1). Further, the linear correlation between the depth of the fluoride ions and 
the reciprocal of the formation voltage, shown in Fig. 5, suggests that the migration of fluoride ions follows the expected behaviour in amorphous anodic oxide films (1). From the slope of $-87 \mathrm{~V}$ in Fig. 5 , corresponding to $-55\left\{t_{+}+t_{-}\left(u_{\mathrm{F}}-/ u_{\mathrm{O}} 2-\right)\right\}$, the migration rate of fluoride ions relative to $\mathrm{O}^{2-}$ ions is 2.0 . Thus, fluoride ions migrate inward at a rate twice that of $\mathrm{O}^{2-}$ ions.

As a consequence of the rapid inward migration of fluoride ions, fluoride ions accumulate at the interface between the anodic oxide and the alloy substrate. The progressive accumulation of fluoride in this region reduces the adhesion of the anodic film. Indeed, partial detachment of the anodic film was evident after anodizing the present alloy to $100 \mathrm{~V}$ in 0.1 mol dm${ }^{-3}$ ammonium fluoride electrolyte; conversely, the anodic film was strongly adherent at a reduced formation voltage of $50 \mathrm{~V}$.

\subsection{Ionic transport in growing amorphous anodic oxides}

At high efficiency, the anodic oxide grows at the alloy/film and film/electrolyte interfaces by simultaneous migration of anions inward and cations outward respectively. Such unusual ionic transport is characteristic of anodic oxides of amorphous structure [33]. Examples include anodic aluminium oxide, bismuth oxide, niobium oxide, tantalum oxide and tungsten oxide. In these anodic oxides, the migrations of anions and cations but are cooperative, not independent, with the orders of anions and cations conserved [34]. Among the various models proposed to explain the ionic transport processes involved in anodic growth, including the hopping transport mechanism of Verwey [35], the place exchange mechanism of Lanyon and Trapnell [36] or Sato and Cohen [37], the non-simultaneous place exchange mechanism of Fromhold [38], a "liquid droplet” model of Mott [39] appears to be most appropriate. In the last model, a small number of ions, say 20, are activated into a state in which their vibrations are sufficient to act as a liquid. In this condition, both cations and 
anions can move under the influence of field, giving comparable transport numbers. Although theoretical treatment of the liquid droplet model is awaited, the model has been supported by several studies, where various mobile tracers have been incorporated into anodic aluminium oxide, titanium oxide and tantalum oxide from the electrolyte or the substrate. Good correlation has been revealed between the migration rate of the outwardly migrating species and their single metal-oxygen bond energies [24, 40]. The results indicate that dissociation of the metal-oxygen bonds is a key step in the ionic transport process under the high electric field at ambient temperatures. The anion species that migrate toward the metal/film interface also have a particular mobility. For instance, phosphate anions have a reduced inward migration rate relative to $\mathrm{O}^{2-}$ ions in anodic aluminium oxide, titanium oxide and tantalum oxide [18, 23, 30]. Additionally, the migration rates of halide ions in growing anodic aluminium oxide decrease with increasing ionic radius. Thus, the faster migration rate of fluoride ions relative to that of $\mathrm{O}^{2-}$ ions may be attributed to the smaller ionic radius of the former ion $(0.119 \mathrm{~nm})$ compared with the latter $(0.126 \mathrm{~nm})$.

In the present study, the inward migration rate of fluoride ions is twice that of $\mathrm{O}^{2-}$ ions in growing anodic titanium oxide. This migration rate of fluoride ions is similar to that in growing anodic tantalum oxide. Phosphate anions also show similar migration rates in the two anodic oxides. From comparison of the mobility of phosphate anions in various anodic oxides, it is suggested that the migration rate decreases as the effective (Lorenz) field increases [23]. The similar migration rates of fluoride ions in anodic $\mathrm{TiO}_{2}$ and $\mathrm{Ta}_{2} \mathrm{O}_{5}$ may also be associated with similar effective field strengths in the respective anodic oxides.

\section{Conclusions}

In growing anodic amorphous titanium oxide, stabilized with incorporated silicon species, fluoride ions migrate inward at a rate greater than that of $\mathrm{O}^{2-}$ ions, developing a thin 
layer of increased fluoride content between the anodic oxide and the metal substrate. The migration rate of fluoride ions, determined by their incorporation into a relatively thick preformed anodic oxide and subsequent film growth at nearly $100 \%$ efficiency, is twice that of $\mathrm{O}^{2-}$ ions.

\section{Acknowledgments}

Thanks are due to Mr. T. Nakamura for the provision of time on Jovin Yvon RF5000 GDOES instrument. The present work was supported in part by a Grant-in-Aid for Scientific Research, No. 16360353 from the Japan Society for the Promotion of Science.

\section{References}

[1] G.K. Mor, O.K. Varghese, M. Paulose, K. Shankar, C.A. Grimes, Sol. Energy Mater., 90 (2006) 2011.

[2] V. Zwilling, M. Aucouturier, E. Darque-Ceretti, Electrochim. Acta, 45 (1999) 921.

[3] D. Gong, C.A. Grimes, O.K. Varghese, W.C. Hu, R.S. Singh, Z. Chen, E.C. Dickey, J. Mater. Res., 16 (2001) 3331.

[4] A. Ghicov, H. Tsuchiya, J.M. Macak, Electrochem. Commun. 7 (2005) 505.

[5] J. M. Macak, K. Sirotna, P. Schmuki, Electrochim. Acta 50, (2005) 3679

[6] Q. Cai, M. Paulose, O.K. Varghese, C.A. Grimes,J.Mat. Res., 20 (2005) 230

[7] R. Beranek, H. Hildebrand, P. Schmuki, Electrochem. Solid State Let., 6 (2003) B12.

[8] J. M. Macak, H. Tsuchiya, P. Schmuki, Angew. Chem. Int. Ed., 44 (2005) 2100.

[9] J.M. Macak, H. Tsuchiya, L. Taveira, S. Aldabergerova, P. Schmuki, Angew. Chem. Int. Ed., 44 (2005) 7463.

[10] S. Albu, A. Ghicov, J.M.Macak, P. Schmuki, Phys. Stat. Sol., 1 ( 2007) R65.

[11] G.K. Mor, K. Shankar, M. Paulose, O.K. Varghese, C.A. Grimes, Nano Letters, 6 (2006) 
215.

[12] M. Paulose, G.K. Mor, O.K. Varghese, K. Shankar, C.A. Grimes, J. Photochemistry and Photobiology, 178 (2006) 8.

[13] C.K. Varghese, M. Paulose, K. Shankar, G.K. Mor, C.A. Grimes, J. Nanosci. Nanotech., 5 (2005) 1158.

[14] G.K. Mor, K. Shankar, M. Paulose, O.K. Varghese, C.A. Grimes, Nano Letters, 5 (2005) 191.

[15] G.K. Mor, K. Shankar, O.K. Varghese, C.A. Grimes, J. Mater. Res., 19 (2004) 2989.

[16] O.K. Varghese, D.W. Gong, M. Paulose, K.G. Ong, C.A. Grimes, Sensors and Actuators B, 93 (2003) 338.

[17] L.V. Taveira, J.M. Macak, K. Sirotna, L.F.P. Dick, P. Schmuki, J. Electrochem. Soc., 153 (2006) B137.

[18] K. Shimizu, K. Kobayashi, G.E. Thompson, P. Skeldon, G.C. Wood, Phil. Mag. B, 73 (1996) 461.

[19] K. Shimizu, K. Kobayashi, G.E. Thompson, P. Skeldon, G.C. Wood, J. Electrochem. Soc., 144 (1997) 418.

[20] C.K. Dyer, J.S.L. Leach, J. Electrochem. Soc., 125 (1978) 1032.

[21] H. Habazaki, M. Uozumi, H. Konno, K. Shimizu, P. Skeldon, G.E. Thompson, Corros. Sci., 45 (2003) 2063.

[22] H. Habazaki, K. Takahiro, S. Yamaguchi, K. Shimizu, P. Skeldon, G.E. Thompson, G.C. Wood, Philos. Mag. A, 78 (1998) 171.

[23] H. Habazaki, K. Shimizu, S. Nagata, P. Skeldon, G.E. Thompson, G.C. Wood, Corros. Sci., 44 (2002) 1047.

[24] H. Habazaki, K. Shimizu, S. Nagata, P. Skeldon, G.E. Thompson, G.C. Wood, J. Electrochem. Soc., 149 (2002) B70. 
[25] H. Habazaki, M. Uozumi, H. Konno, S. Nagata, K. Shimizu, Surf. Coat. Technol., 169 (2003) 151.

[26] H. Habazaki, M. Uozumi, H. Konno, K. Shimizu, S. Nagata, K. Asami, K. Matsumoto, K. Takayama, Y. Oda, P. Skeldon, G.E. Thompson, Electrochim. Acta, 48 (2003) 3257.

[27] H. Habazaki, M. Uozumi, H. Konno, K. Shimizu, S. Nagata, K. Takayama, Y. Oda, P. Skeldon, G.E. Thompson, J. Electrochem. Soc., 152 (2005) B263.

[28] K. Wagatsuma, K. Hirokawa, N. Yamashita, Anal. Chim. Acta, 324 (1996) 147.

[29] M.T. Tanvir, K. Fushimi, K. Shimizu, S. Nagata, P. Skeldon, G.E. Thompson, H. Habazaki, Electrochim. Acta, to be submitted.

[30] G.C. Wood, P. Skeldon, G.E. Thompson, K. Skeldon, J. Electrochem.Soc., 143 (1996) 74.

[31] H. Habazaki, T. Matsuo, H. Konno, K. Shimizu, S. Nagata, K. Matsumoto, K. Takayama, Y. Oda, P. Skeldon, G.E. Thompson, Electrochim. Acta, 48 (2003) 3519.

[32] N. Khalil, J.S.L. Leach, Electrochim. Acta, 31 (1986) 1279.

[33] J.P.S. Pringle, Electroche. Acta, 25 (1980) 1420.

[34] G. Amsel, D. Samuel, J. Phys. Chem. Solids, 1962 (1962) 1707.

[35] E.J.W. Verwey, Physica, 2 (1935) 1059.

[36] M.A.H. Lanyon, B.M.W. Trapnell, Proc. Roy. Soc., 227 (1955) 387.

[37] N. Sato, M. Cohen, J. Electrochem. Soc., 111 (1964) 512.

[38] A.T. Fromhold, J. Electrochem. Soc., 127 (1980) 411.

[39] N.F. Mott, Phil. Mag. B, 55 (1987) 117.

[40] K. Shimizu, K. Kobayashi, J. Surf. Finish. Soc. Jpn., 46 (1995) 402. 
Figure captions

Fig. 1 Schematic diagrams showing the distributions of the silicon marker species and fluoride ions in the films used for determination of the migration rate of fluoride ions: (a) film formed to $50 \mathrm{~V}$ in ammonium pentaborate electrolyte; (b) fluoride incorporation by subsequent anodizing to $55 \mathrm{~V}$ in ammonium fluoride electrolyte; (c) after further anodizing in ammonium pentaborate electrolyte.

Fig. 2 Voltage-time responses of the sputter-deposited Ti-12 at\% Si alloy during anodizing to $50 \mathrm{~V}$ at a constant current density of $50 \mathrm{~A} \mathrm{~m}^{-2}$ in $0.1 \mathrm{~mol} \mathrm{dm}^{-3}$ ammonium pentaborate and $0.1 \mathrm{~mol} \mathrm{dm}^{-3}$ ammonium fluoride electrolytes at $293 \mathrm{~K}$.

Fig. 3 GDOES depth profiles of the anodic film formed to $50 \mathrm{~V}$ at a constant current density of $50 \mathrm{~A} \mathrm{~m}^{-2}$ in $0.1 \mathrm{~mol} \mathrm{dm}^{-3}$ ammonium fluoride electrolyte at $293 \mathrm{~K}$.

Fig. 4 GDOES depth profiles of the anodic films formed by three-stage anodizing, comprising initial anodizing to $50 \mathrm{~V}$ at $50 \mathrm{~A} \mathrm{~m}^{-2}$ in $0.1 \mathrm{~mol} \mathrm{dm}^{-3}$ ammonium pentaborate electrolyte, reanodizing to $55 \mathrm{~V}$ at $10 \mathrm{~A} \mathrm{~m}^{-2}$ in $0.1 \mathrm{~mol} \mathrm{dm}^{-3}$ ammonium fluoride electrolyte and final anodizing to (a) $80 \mathrm{~V}$ and (b) $100 \mathrm{~V}$ at $50 \mathrm{~A} \mathrm{~m}^{-2}$ in $0.1 \mathrm{~mol} \mathrm{dm}^{-3}$ ammonium pentaborate electrolyte at $293 \mathrm{~K}$.

Fig. 5 Correlation between the depth of the fluoride band, $d / d_{0}$, and the reciprocal of the formation voltage, I/E. 
Table 1 Thickness, composition and density of the anodic film formed to $100 \mathrm{~V}$ in $0.1 \mathrm{~mol}$ $\mathrm{dm}^{-3}$ ammonium pentaborate electrolyte at $293 \mathrm{~K}$ [29].

\begin{tabular}{lclc}
\hline & Thickness $(\mathrm{nm})$ & Composition & Density $\left(\mathrm{Mg} \mathrm{m}^{-3}\right)$ \\
\hline Outer layer & 82 & $\mathrm{TiO}_{2}$ & 3.8 \\
Inner layer & 113 & $\left(\mathrm{Ti}_{0.8} \mathrm{Si}_{0.2}\right) \mathrm{O}_{2}$ & 3.6 \\
\hline
\end{tabular}

* Presence of boron species in the outer part of anodic film is neglected. 


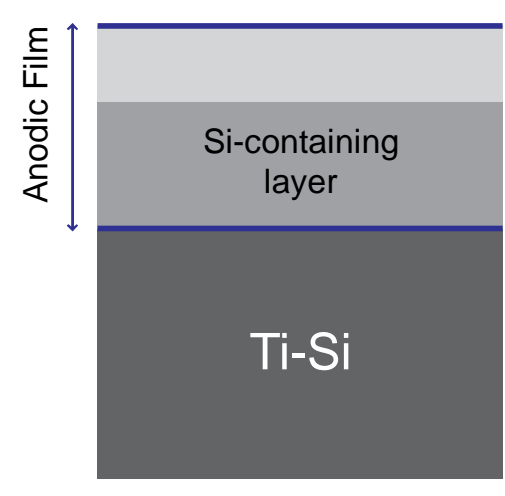

(a)

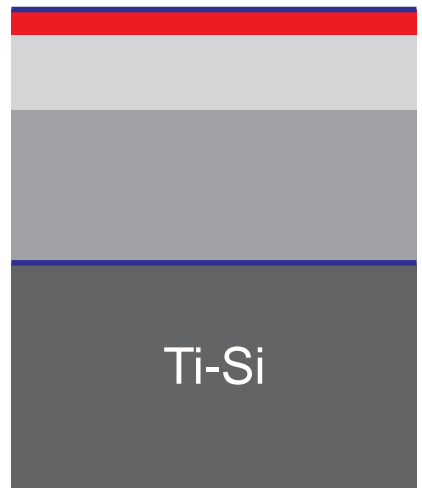

(b)

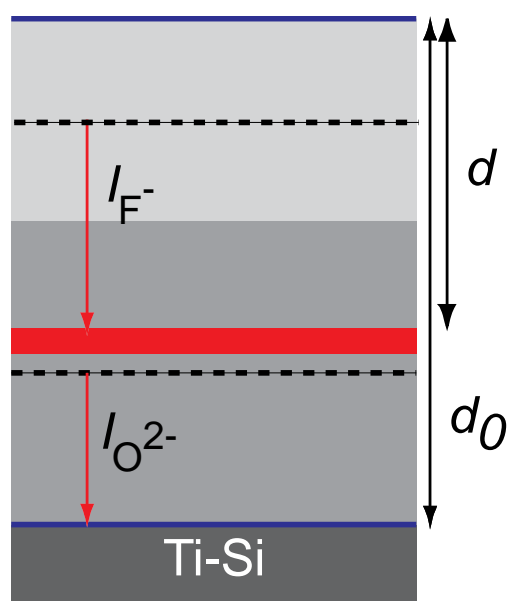

(c)

Fig. 1 


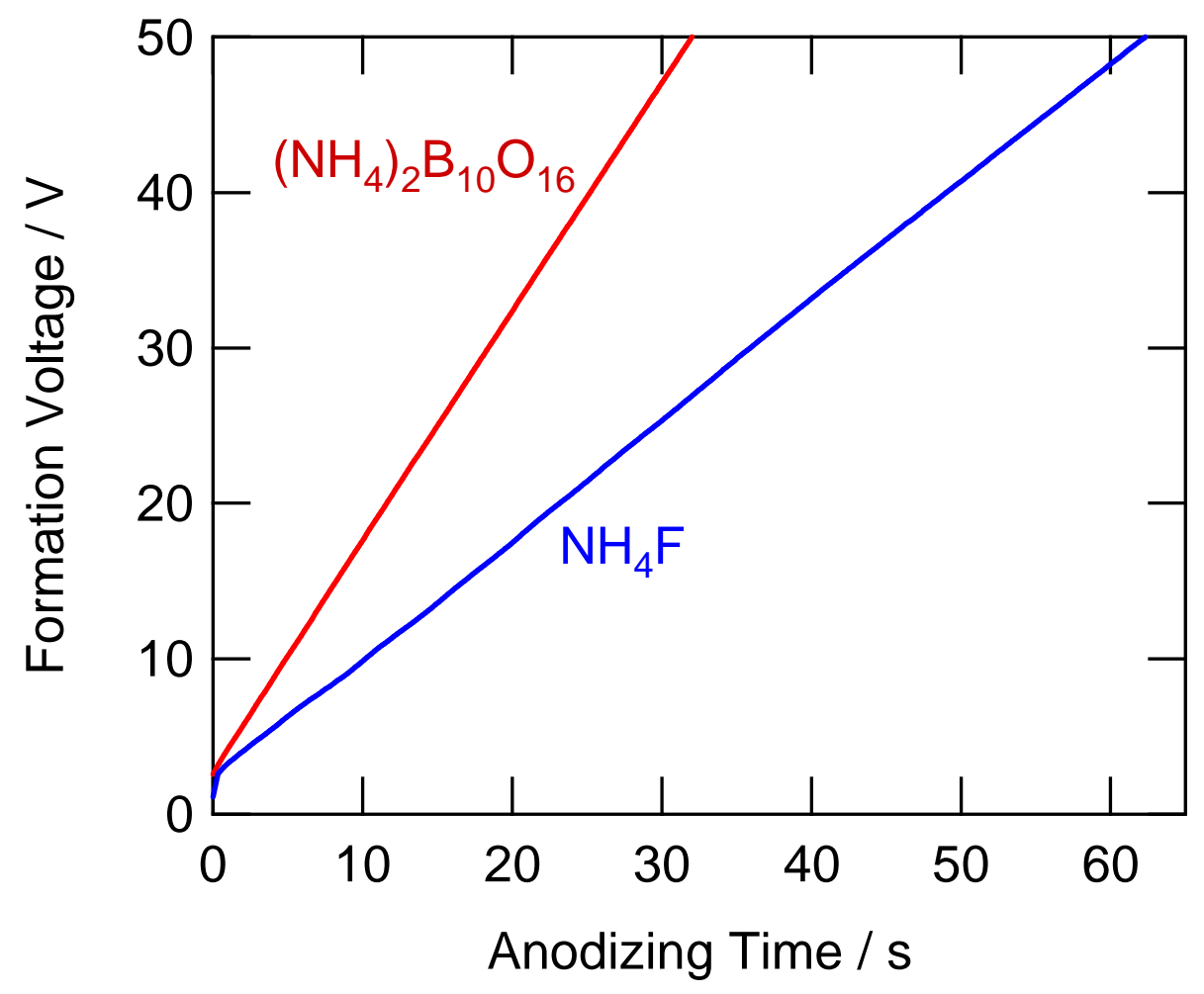

Fig. 2 


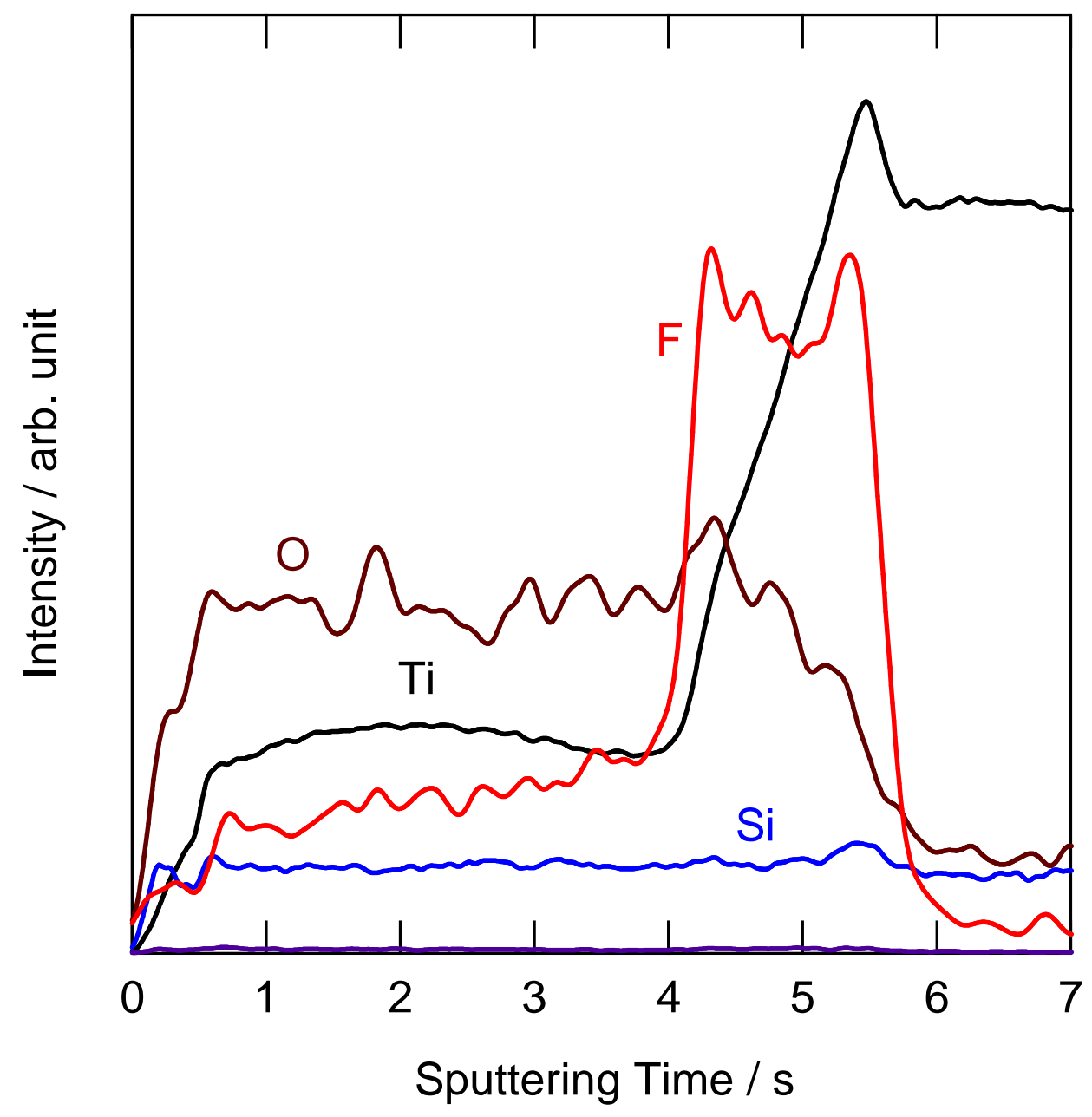

Fig. 3 

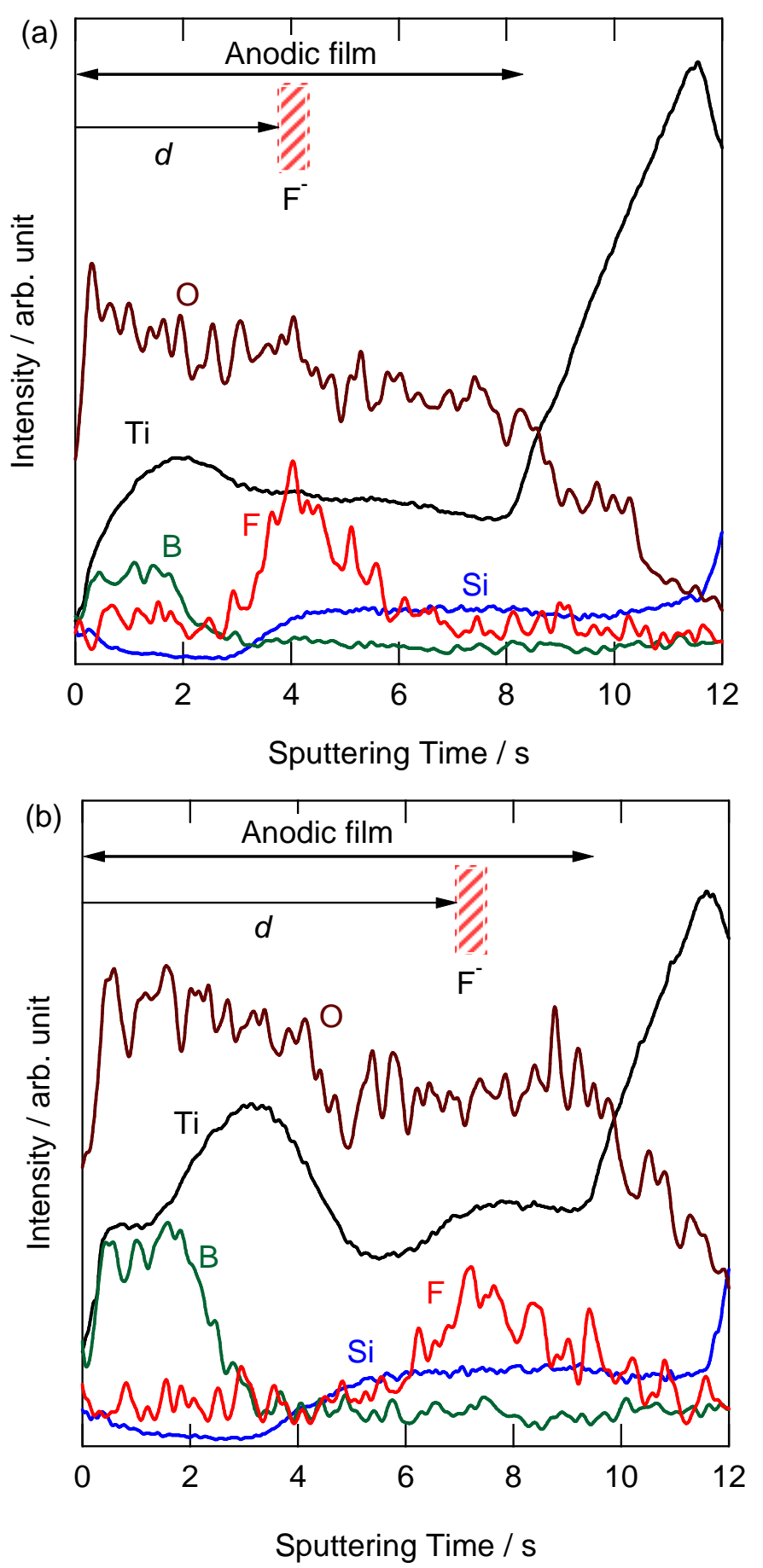

Fig. 4 


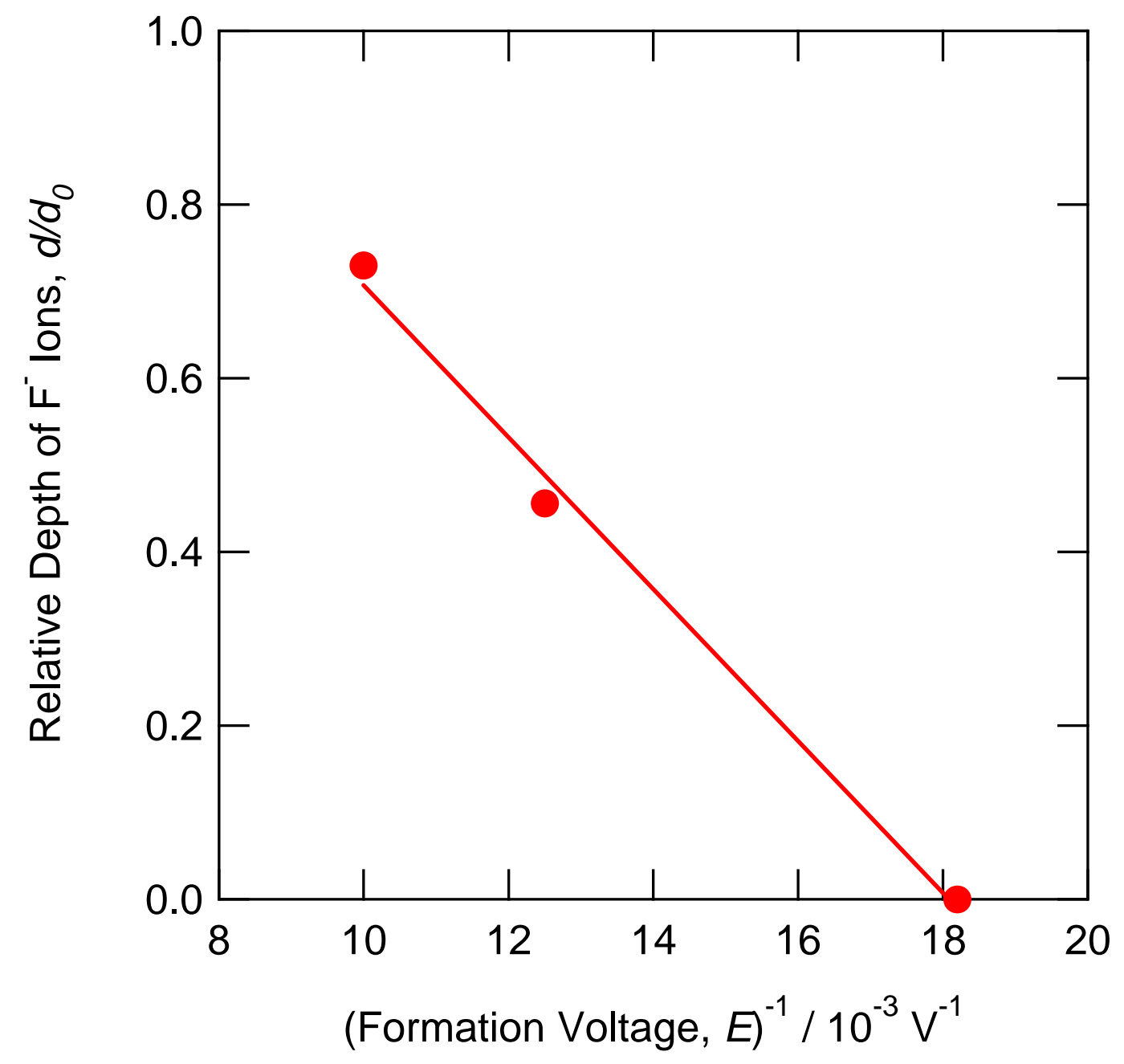

Fig.5 